\title{
KNOWLEDGE REGARDING HIVIAIDS AMONG PREGNANT FEMALES ATTENDING ANTENATAL CLINIC AT KHYBER TEACHING HOSPITAL PESHAWAR, PAKISTAN
}

\author{
Fatima $\mathbf{S}^{1}$, Afridi $\mathrm{NK}^{2}$, Khan $\mathbf{S}^{3}$ \\ 1 Khyber Teaching Hospital, Peshawar, Pakistan \\ SAARC TB \& HIVIAIDS Centre, Kathmandu, Nepal \\ 3 Federal Medical Centre, Peshawar, Pakistan
}

\begin{abstract}
Introduction: Globally, around 34 million people are living with HIV in 2010, and $35 \%$ of the pregnant women are tested for HIV in the low and middle income countries. HIV infection in pregnancy has become a complication of pregnancy in some developing countries. This has major implications for the management of pregnancy and birth. With an estimated one and a half million HIV-positive women becoming pregnant each year, almost 600,000 children will be infected by mother-to-child transmission annually.
\end{abstract}

Methodology: A cross sectional study was conducted from October - December 2011 in the Department of Obstetrics and Gynecology, Khyber Teaching Hospital, Peshawar. It is a tertiary care hospital located in Peshawar. A sample of 200 pregnant females was used to accomplish the study. The targeted study population was all antenatal attendees who were visiting the hospital within the current pregnancy. A precoded, pre- tested structured questionnaire was used to gather information on the study variables. The questionnaire included variables related socio-demographics e.g., age, education status, occupation, residence. It also included the gestational age and gravidity of the pregnant females.

Results: A total of 200 pregnant females attending the antenatal clinic participated in the study. The age range of the respondents was 17 to 45 years. Age range 17-25 years accounted for the highest percentage (52\%). Around $70 \%$ of the respondents had no formal schooling while only $18 \%$ had got secondary education. Ninety - seven percent of the females were housewives while only $3 \%$ were employed. Out of the total respondents (200) only $86(43 \%)$ have heard of HIV while $114(57 \%)$ respondents have not heard of HIV.

Conclusion: The study concluded that only $43 \%$ of the pregnant females have heard of HIV. Although this is not promising still there is room for improvement. Health education targeting pregnant females is essential.

\section{INTRODUCTION}

Globally, around 34 million people are living with HIV in 2010 , and $35 \%$ of the pregnant women are tested for HIV in the low and middle income countries. ${ }^{1}$ The United Nations General Assembly Special Session (UNGASS), in 2001,

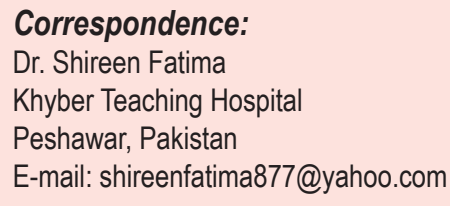

put a clear emphasis on the effect of HIVIAIDS on maternal and child health. The final declaration of commitment from the assembly stated that the proportion of infants infected with HIV should be reduced by $20 \%$ by 2005 , and by $50 \%$ by $2010 .{ }^{2}$

HIV infection in pregnancy has become a complication of pregnancy in some developing countries. This has major implications for the management of pregnancy and birth. With an estimated one and a half million HIV-positive women becoming pregnant each year, almost 600 , 
000 children will be infected by mother-to-child transmission annually. ${ }^{3}$

HIV is transmitted mainly in three ways: through unprotected sexual intercourse, heterosexual or homosexual; through blood or blood products, donated semen or organs; or from an infected mother to her child (vertical or mother-to-child transmission). More than $70 \%$ of infections are a result of heterosexual transmission and over $90 \%$ of infections in children result from mother-to-child transmission. ${ }^{4}$

Data available from developed countries suggest that pregnancy does not accelerate the progression of HIV disease. A systematic review and metaanalysis of seven cohort studies from 1983 to 1996 suggested that there was an association between adverse maternal outcomes and pregnancy in HIVinfected women. Routine antenatal counseling and testing for HIV, also known as provider-initiated testing approach, involves testing all antenatal attendees for HIV, apart from those who decline the test (i.e., those who opt out). This is the standard of care in Scandinavia and other high-income countries. 5.6 The sub-Saharan countries, in a bid to increase HIV testing rates, routine antenatal HIV counseling and testing was successfully introduced in the HIV prevention programmes of several countries in line with the Joint United Nations Programme on HIVIAIDS (UNAIDS) and World Health Organization (WHO) recommendations. ${ }^{7}$

Wherever possible, voluntary counseling and testing should be available to any pregnant women who request it and offered to all in areas of moderate or high prevalence. Routine testing of pregnant women without consent or without access to counseling is, however, an unacceptable practice and the disadvantages may negate any benefit obtained from knowing the HIV status of the women. These include a reluctance to utilize maternity services through fear of discrimination, denial of a positive diagnosis and stigmatization. Recommendations for mandatory testing of pregnant women or newborns have led to concern about the autonomy and rights of women. ${ }^{8,9}$ Complications of early pregnancy have been associated with HIV infection in several studies. ${ }^{10,11}$
HIV-1 and HIV-2 infection in Africa have both been linked to a higher rate of spontaneous abortion. HIV sero-positive women were 1.47 times more likely to have had a previous spontaneous abortion and this rose to 1.81 in women in Uganda who were seropositive for both HIV and syphilis. ${ }^{12}$

In many developed countries, HIV testing, antiretroviral therapy and infant feeding modifications have been used to virtually eliminate mother-to-child transmission of HIV yet SubSaharan Africa continues to be heavily affected due to lack of knowledge, testing services and antiretroviral therapy. ${ }^{13}$

It has been observed that most of the individuals in community do not have correct and complete information about HIV/ AIDS and its prevention. And many of the female population are unaware about correct knowledge of HIVIAIDS. The study was conducted with the aim to determine the knowledge of pregnant females regarding HIVI AIDS attending a tertiary care hospital in Peshawar.

\section{METHODOLOGY}

A cross sectional study was conducted from October - December 2011 in the Department of Obstetrics and Gynecology, Khyber Teaching Hospital, Peshawar. It is a tertiary care hospital located in Peshawar. A sample of 200 pregnant females was used to accomplish the study. The sample size was calculated by assuming that knowledge level of the females on HIVIAIDS being $20 \%$ and the maximum acceptable difference from true value is. 06 , then for a significance value of $5 \%$, the sample size came out to be 171. To account for non-response the sample size was inflated by $15 \%$ to give the sample size of 197 . The final sample size was 200.

The targeted study population was all antenatal attendees who were visiting the hospital within the current pregnancy. Women, who were very sick, requiring urgent medical attention, were excluded from the study. Consent was taken from each of the women before starting the interview.

A pre- coded, pre- tested structured questionnaire 
was used to gather information on the study variables. The questionnaire included variables related socio-demographics e.g., age, education status, occupation, residence. It also included the gestational age and gravidity of the pregnant females. The variables related to knowledge, attitude and practices were whether heard of HIV, source of information, whether HIV transmitted by kissing, sharing food, mosquito bite, through contaminated needles, blood products, breast milk etc. The interviews were conducted in local language. The principal investigator checked filled questionnaires for completeness at the end of each day.

Data was entered and analyzed in SPSS version 16.0. Descriptive analysis of frequencies and percentages were generated for the variables. The association between different variables was determined using chi square test and the significance level was set at 0.05 .

\section{RESULTS}

A total of 200 pregnant females attending the antenatal clinic participated in the study. The age range of the respondents was 17 to 45 years. Age range 17-25 years accounted for the highest percentage (52\%) while those 36 - 45 years of age group accounted for $5 \%$ (Figure 1). Around $70 \%$ of the respondents had no formal schooling while only $18 \%$ had got secondary education. Ninety seven percent of the females were housewives while only $3 \%$ were employed.

It was observed that majority of the antenatal women $142(71 \%)$ were registered for antenatal check up in the third trimester while only $18(09 \%)$ came for antenatal registration / check up in the first trimester. The participants who were first, second to fourth and more than four gravida were $32 \%, 39 \%$ and $29 \%$ respectively.

Out of the total respondents (200) only $86(43 \%)$ have heard of HIV while $114(57 \%)$ respondents have not heard of HIV (Figure 2). The rest of the questionnaire was administered only to those participants who have heard of HIV while the participants who have not heard of HIV were given a brief introduction of HIV IA IDS and its prevention. Regarding source of information of HIV around $74 \%$ of the participants reported that the main source of information was mass media followed by friend/relative $(21 \%)$ as reported by the participants (Figure 3). Table 1 summarizes the knowledge regarding HIV of pregnant women who have heard of HIV. Although most of the responses given by the participants were correct yet a few misconceptions still exists as evident by the responses. Around $44 \%$ of the participants responded that HIV can be transmitted by kissing/ hugging, $36 \%$ believed that clothes can act as an agent in the transmission of HIV while $32 \%$ responded that sharing/ eating food can transmit HIV. A higher percentage of participants responded that HIV transmission can occur due to sex with person having HIV (84\%), contaminated needle/syringe (87\%), contaminated blood transfusion $(92 \%)$ and HIV infected mother to child transmission (70\%).

Table 2 depicts association between two variables i.e., heard of HIV and age category, it shows that the association between the two variables are not significant $p$-value $(0.54)$ so different age categories have no association with the variable heard of HIV.

Table 3 depicts the association between two variables i.e., heard of HIV and education status categories. And it was found the two variables are highly significant $p$-value $(0.000)$, it was also evident that around $71 \%$ of the women who have not heard of HIV have no formal schooling. It is also interesting to note as the education level becomes higher then more females are educated and have heard of HIV.

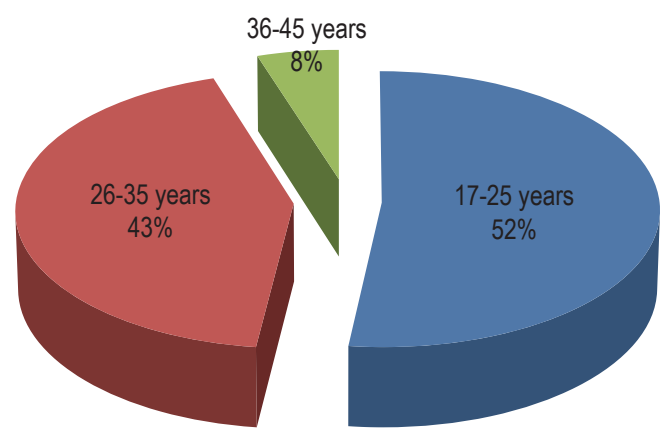

Figure 1. Age distribution of the pregnant females 


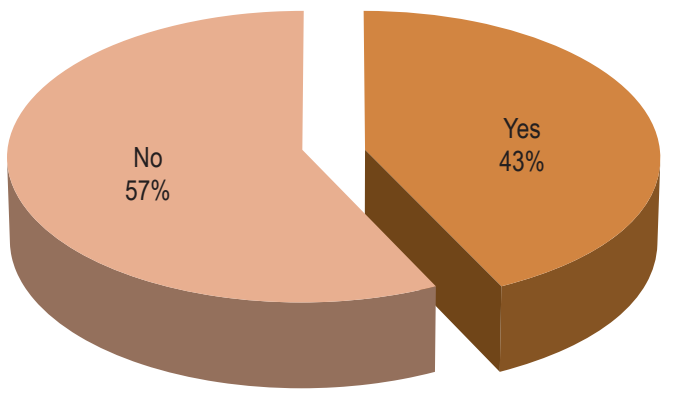

Figure 2. Knowledge regarding HIV

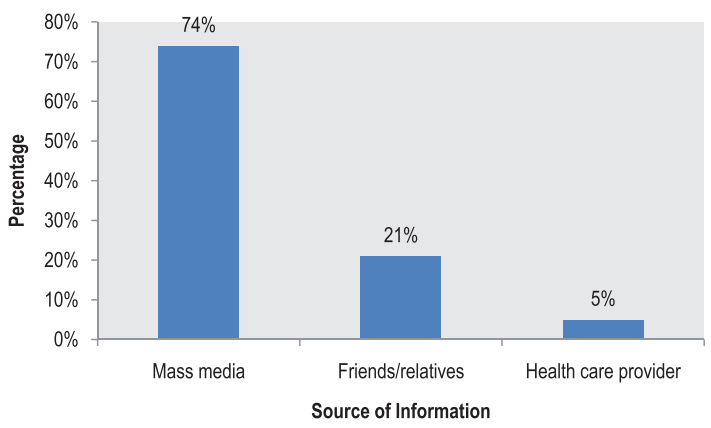

Figure 3. Source of Information regarding HIV

\begin{tabular}{|c|c|}
\hline Variables & Number (\%) \\
\hline \multicolumn{2}{|c|}{ HIV transmitted by kissing/hugging } \\
\hline Yes & $38(44)$ \\
\hline No & $48(56)$ \\
\hline \multicolumn{2}{|l|}{ HIV transmitted by clothes } \\
\hline Yes & $31(36)$ \\
\hline No & $55(64)$ \\
\hline \multicolumn{2}{|c|}{ HIV transmitted by eating food with HIV person } \\
\hline Yes & $28(32)$ \\
\hline No & $58(68)$ \\
\hline \multicolumn{2}{|c|}{ HIV transmitted by having sex with HIV person } \\
\hline Yes & $72(84)$ \\
\hline No & $14(16)$ \\
\hline \multicolumn{2}{|c|}{ HIV transmitted by bite of mosquito } \\
\hline Yes & $58(67)$ \\
\hline No & $28(33)$ \\
\hline \multicolumn{2}{|c|}{ HIV transmitted by contaminated needle/syringe } \\
\hline Yes & $75(87)$ \\
\hline No & $11(13)$ \\
\hline \multicolumn{2}{|c|}{ HIV transmitted by contaminated blood transfusion } \\
\hline Yes & $79(92)$ \\
\hline No & $07(08)$ \\
\hline \multicolumn{2}{|c|}{ HIV transmitted by HIV mother to child } \\
\hline Yes & $60(70)$ \\
\hline No & $26(30)$ \\
\hline
\end{tabular}

\begin{tabular}{|l|l|}
\hline \multicolumn{2}{|l|}{ HIV transmitted through breast milk } \\
\hline Yes & $48(56)$ \\
\hline No & $38(44)$ \\
\hline Condom prevent HIV transmission \\
\hline Yes & $35(41)$ \\
\hline No & $51(59)$ \\
\hline AIDS curable disease & $40(46)$ \\
\hline Yes & $46(54)$ \\
\hline No
\end{tabular}

Table 2. Cross Tabulation between Age group and heard about HIV $(n=200)$

\begin{tabular}{|l|c|c|}
\hline & \multicolumn{2}{|c|}{ Heard of HIV } \\
\hline Age Group & Yes & No \\
\hline $17-25$ years & $41(40 \%)$ & $62(60 \%)$ \\
\hline $26-35$ years & $39(45 \%)$ & $47(55 \%)$ \\
\hline $36-45$ years & $6(55 \%)$ & $5(45 \%)$ \\
\hline
\end{tabular}

$x^{2}: 1.22$

p-value: 0.54

Table 3. Cross Tabulation between Education status and heard about HIV $(n=200)$

\begin{tabular}{|l|c|c|}
\hline \multirow{2}{*}{\multicolumn{2}{|c|}{ Education category }} & \multicolumn{2}{c|}{ Heard of HIV } \\
\cline { 2 - 3 } & Yes & No \\
\hline No formal schooling & $41(29 \%)$ & $98(71 \%)$ \\
\hline Primary schooling & $06(60 \%)$ & $04(40 \%)$ \\
\hline Secondary schooling & $25(69 \%)$ & $11(31 \%)$ \\
\hline Above Secondary schooling & $14(93 \%)$ & $01(07 \%)$ \\
\hline
\end{tabular}

$X^{2}: 1.22$

p-value: 0.000

\section{DISCUSSION}

Knowledge of HIVIAIDS among pregnant females was not appreciably high as $57 \%$ have not heard of HIVIAIDS. Only $43 \%$ of the pregnant females have heard of HIV. These findings are also shown in a study conducted by Singh where about $40 \%$ of pregnant women had heard of AIDS. ${ }^{14}$ One of the most important finding in this study was that education levels play a significant role in awareness regarding HIVIAIDS. So the higher educational status of pregnant women was associated with the increase in awareness towards HIVIAID. Similar findings are reported by a number of studies conducted. ${ }^{15,16}$

The main source of information regarding HIV/ AIDS was mass media (74\%) and many studies 
have corroborated this finding. The significance of information, education and communication in prevention and control of HIVIAIDS had been advocated. ${ }^{17}$

Misconceptions regarding HIVIAIDS are still prevalent as $44 \%$ of the participants believed that HIV is transmitted by kissing/hugging, $36 \%$ responded that it is spread by wearing clothes of infected person. There was also misconception about eating food with HIV infected person and mosquitoes' bite can transmit HIV infection. The issue of misconceptions was also highlighted in various studies. ${ }^{18,19}$ Lack of precise and correct information and knowledge about sexual health has resulted in myths and misconceptions about sex and HIV, contributing to increasing transmission rates as well as stigma and discrimination towards people living with HIVIAIDS.

Approximately $50 \%$ of the pregnant females belong to $17-25$ years age group and giving them health at this stage might help them in preventing themselves and their newborns from the risk of HIVIAIDS. A study conducted in Pakistan also showed that $58.7 \%$ of the participants responded that use of condom can prevent the transmission of HIVIAIDS while in this study $41 \%$ responded that condom can prevent HIV. ${ }^{20}$

Whereas breastfeeding carries significant health benefits to infants and young children, HIV can

be transmitted during breastfeeding from an HIVinfected mother to her infant. Reducing this

transmission while ensuring improved HIV-free survival is one of the most pressing public health dilemmas confronting researchers, health-care professionals, health policy-makers and HIVinfected women in many areas of the world, especially in developing countries. Mother-to-child transmission of HIV can occur during pregnancy, labour or delivery, or through breastfeeding. Without specific interventions, HIV-infected women will pass the virus to their infants during pregnancy or delivery in about $15-25 \%$ of cases; and an additional $5-20 \%$ of infants may become infected postnatally during breastfeeding, for an overall risk of $30-45 \%$.
Breastfeeding may thus be responsible for one third to one half of HIV infections in infants when interventions are not available. ${ }^{21}$

Areas of concern include the low level of knowledge gained directly from health care workers and only $04(05 \%)$ of the pregnant females responded that they have heard HIV from health care workers. There is a perturbing lack of knowledge about the breastfeeding routes of transmission particularly as the participants were pregnant women, as $56 \%$ responded that HIV can be transmitted through breast milk. Awareness that condoms can prevent HIV transmission was relatively low $41 \%$ and also that $46 \%$ responded that AIDS is a curable disease is also alarming. These areas should form part of the health education imparted during each antenatal session and should be supported with the use of audio-visual aids.

Although the scientific community are struggling to find a long lasting cure for HIVIAIDS, till now there is no effective treatment available nor has a vaccine breakthrough been made for HIVIAIDS. Advocacy, general awareness, heath education, safe sex practices, screening of blood products are the best recommended practices.

\section{CONCLUSION}

The study concluded that only $43 \%$ of the pregnant females have heard of HIV. Although this is not promising still there is room for improvement. Health education targeting pregnant females is essential. Awareness campaigns regarding HIV/ AIDS involving mass media and through health care providers can be helpful and beneficial in prevention and spread of HIVIAIDS.

\section{REFERENCES}

1. World Global HIVIAIDS response, Progress Report, World Health Organization, 2011.

2. United Nations General Assembly. Final declaration of commitment on HIVIAIDS, New York: 2001 http://www.Unaids.Org/UNGASS/index.html.

3. UNAIDS. Report on the Global HIVIAIDS epidemic. Geneva, Joint United Nations Programme on HIVI AIDS, 1997:1-13. 
4. Fowler MG, Melnick SL, Mathieson BJ. Women and HIV. Epidemiology and global overview. Obstet Gynecol Clin North Am, 1997;24:705-29.

5. CDC: Revised Recommendations for HIV Screening of Pregnant Women. In MMWR Recomm Rep. Volume 50. Atlanta: CDC; 2001;5986 [http://www. cdc.gov/mmwr/preview/mmwrhtml/ rr5019a2.htm].

6. Sherr L, Fox Z, Lipton M, Whyte P, Jones P, Harrison U, Group CIS: Sustaining HIV testing in pregnancy - Evaluation of routine offer of HIV testing in three London hospitals over 2 years. AIDS Care: Psychological and Socio-medical Aspects of AIDS/HIV 2006; 18:183-88.

7. UNAIDS/WHO: UNAIDS/WHO policy statement on HIV testing Geneva; 2004 [http:// www.who.int / hiv / pub / vct / statement / en/index.html].

8. Minkoff H, Willoughby A. The future of prenatal HIV testing. Acta Pediatr, 1997;421:72-77

9. Minkoff H, Willoughby A. Pediatric HIV disease, zidovudine in pregnancy and unblinding heelstick surveys. JAMA, 1995;274:1165-68.

10. D'Ubaldo C, Pezzotti P, Rezza G et al. Association between HIV-1 infection and miscarriage: a retrospective study. AIDS, 1998;12:1087-93.

11. Langston C, Lewis DE, Hammill HA et al. Excess intrauterine fetal demise associated with maternal human immunodeficiency virus infection. J Infect Dis, 1995;172:1451-60.

12. Byabamazina CR, Asiimwe OG, Malamba $S$ et al. HIV/Syphilis serology as an indicator of past pregnancy outcomes among antenatal attendees in Kampala. IXth International Conference on AIDS and STD in Africa, Kampala, 1995, Abstract TuC108.
13. US Aids for International Development (USAID). Nigeria a Country profile (HIVIAIDS); 2003 www. usaid.gov / acations / sub_sahara africa/countries/ nigeria.

14. Singh S, Fukuda H, Ingle Gk, Tatara K. Knowledge, attitude, the perceived risks of infection and sources of information about HIVIAIDS among pregnant women in an urban population of Delhi. $\mathrm{J}$ Commun Dis 2002;34:23-34.

15. Ambati BK, Ambati $\mathrm{J}$ and Rao AM. Dynamics of knowledge and attitudes about AIDS among the educated in Southern India. AIDS Care 1997;9:31930.

16. Jacob KS, Jayakumari $H$, Jacob K John, Jacob John T. Awareness of AIDS in India: effect of public education through the mass media. BMJ 1989;229:721.

17. Femi Oyewo MN. Information, Education and Comunication in the Prevention and Control of HIV/ AIDS. West Afr. J.Pharm. 2003;1:25-32.

18. Ojieabu WA, Erah PO, Okafor NA. HIVIAIDS knowledge and sexual behaviour. Int J Health Res. March 2008;1:35

19. Bhattacharya GC, Cleland, and Holland. Knowledge about HIVIAIDS, the perceived risks of infection and sources of information of AsianIndian born in the USA. AIDS Care 2000;2:203-09.

20. Gulfareen Haider, Nishat Zohra, Nusrat Nisar, Aftab Afroz Munir . Knowledge about AIDS/HIV infection among women attending obstetrics and gynaecology clinic at a university hospital. JPMA 2009;59:95

21. World Health Organization, 2008. HIV transmission through breastfeeding: a review of available evidence - an update from 2001 to 2007. 